${ }^{7}$ Lobo PI, Spencer CI. Inhibition of humoral and cell mediated responses in man by distinct suppressor cell systems. $\mathcal{f}$ Clin Invest 1979;63:1157.

${ }^{8}$ Seigel S. Non parametric statistics for the behavioral sciences. New York: McGraw-Hill, 1956:95-158.

${ }^{9}$ Moretta L, Webb S, Grossi CE, Lydyard PM, Cooper MD. Functional analysis of two human lymphocyte populations: help and suppression of $\mathrm{B}$ cell responses by $\mathrm{T}$ cells bearing receptors for IgM or IgG. F Exp Med 1977;146:184-200.

${ }^{10}$ Kung PC, Goldstein G, Reinherz EL, Schossman SF. Monoclonal antibodies defining distinctive human $\mathrm{T}$ cell surface antigens. Science $1979 ; 206: 347-9$

${ }^{11}$ Ishizaka K, Adachi T. Generation of specific helper cells and suppressor cells in vitro for the IgE and IgG antibody responses. 7 Immunol 1976; 117:40-7.

12 Johnsen HE, Madsen M, Kristensen T. Lymphocyte sub populations in man: suppression of PWM induced $\mathrm{B}$ cell proliferation by infectious mononucleosis T cells. Scand f Immunol 1979;10:251-5.

${ }^{13}$ Haynes BF, Schooley KT, Payling Wright CK, Grange JE, Dolin R, Fauci AS. Emergence of suppressor cells of immunoglobulin systems during acute Epstein Barr virus induced infectious mononucleosis. f Immunol 1979;123:2095-101.

${ }^{14}$ Royston I, Sullivan JL, Perriman PO, Perlin E. Cell-mediated immunity to Epstein Barr virus transformed lymphoblastoid cells in acute infectious mononucleosis. N Engl f Med 1975;293:1159-63.
15 Tosato G, Magrath I, Koski I, Dooley N, Blaese M. Activation of suppressor $\mathrm{T}$ cells during Epstein Barr virus induced infectious mononucleosis. $N$ Engl f Med 1979;301:1133-7.

${ }^{16}$ Reinherz EL, O'Brien C, Rosenthal P, Schlossman SF. The cellular basis for viral induced immunodeficiency: analysing monoclonal antibodies. F Immunol 1980;125:1269-4.

17 Anonymous. Limited immunodeficiency, Lancet 1978;i:132-3.

${ }_{18}$ Bird AG, McLachlan SM, Britten S. Cyclosporin A promotes spontaneous outgrowth in vitro of Epstein Barr virus induced B cell lines. Nature $1981 ; 289: 300-1$

19 Crawford DH, Thomas JA, Janossy G, et al. Epstein Barr virus nuclear antigen positive lymphoma after cyclosporin $A$ treatment in a patient with renal allograft. Lancet $1980 ; \mathrm{i}: 1355-6$

20) Abu W, Tokada K, Kamada $M$, et al. Evolution of infectious mononucleosis into Epstein Barr virus carrying monoclonal malignant lymphoma. Lancet 1982; : $: 1272-5$.

21 Tobi M, Morag A, Ravid Z, et al. Prolonged atypical illness associated with serological evidence of persistent Epstein Barr virus infection. Lancet 1982; :61-4.

${ }^{22}$ Lindsten T, Selley JK, Ballow M, et al. Immune deficiency in the X-linked lymphoproliferative syndrome II. Immunoregulatory $\mathrm{T}$ cell defects. f Immunol $1982 ; 129: 2536-40$.

(Accepted 7 April 1983)

\title{
Factors predictive of attendance at clinic and blood pressure control in hypertensive patients
}

\author{
P DEGOULET, JMENARD, H-A VU, J-L GOLMARD，C DEVRIES，G CHATELLIER, P-F PLOUIN
}

\begin{abstract}
Poor compliance with appointments and drug treatment is one of the recognised factors preventing effective management of hypertension. Factors predictive of poor attendance and inadequate blood pressure control in patients attending a hypertension clinic were therefore determined using univariate analyses and a multivariate logistic model. Out of 1346 patients with blood pressure exceeding $160 / 95 \mathrm{~mm} \mathrm{Hg}$ followed up for three years, $209(15.5 \%)$ dropped out during the first year. Variables that were significantly related to increased drop out rates were male sex, young age, obesity at entry, cigarette smoking, direct referral to the clinic as a result of screening instead of referral by a general practitioner, absence of pre-existing antihypertensive treatment at the first visit, moderate hypertension, and low socioeconomic category. Variables at entry that were significantly related to poor blood pressure control at one year were old age, evidence of coronary heart disease, severe hypertension, and raised blood glucose concentrations.
\end{abstract}

Early detection of patients at high risk of drop out or

Medical Informatics Department and INSERM U194, Hôpital

Pitié-Salpétriè, e 75634 Paris Cédex 13

$P$ DEGOULET, $M D, M S C$, senior lecturer in medical informatics

J-L GOLMARD, MD, lecturer in statistics

C DEVRIES, MD, programme analyst

Hypertension Clinic, Hôpital Broussais, Paris

J MENARD, MD, MSC, associate professor and head of clinic

$\mathrm{H}-\mathrm{A}$ VU, MD, research fellow in medical informatics

G CHATELLIER, MD, research fellow in epidemiology

Hypertension Clinic, Hôpital Saint-Joseph, Paris

P-F PLOUIN, MD, head of clinic

Correspondence to: Dr P Degoulet poor blood pressure control might improve treatment of hypertension and allow management to be more individually adapted to each patient.

\section{Introduction}

In everyday practice the results of medical treatment for permanent arterial hypertension are often considerably poorer than expected. This lack of success is possibly due to inadequate screening to detect hypertension, poor or delayed access to care, inadequate treatment, and, finally, low compliance with drug treatment. ${ }^{1}$ Efforts to improve screening for hypertensive disease and the distribution of care, however, are useless and $\exists$ costly to the community if compliance is poor. ${ }^{2}$

The reasons for poor compliance are numerous. Hypertension is often asymptomatic and may necessitate lifelong treatment that is costly and sometimes poorly tolerated. Improving compliance requires the combined efforts of both the patient $O$ and the doctor. ${ }^{3}$ In this study we determined the risk factors $D$ present at the first visit associated with low compliance with appointments and poor treatment results in hypertensive $\tilde{O}$ patients attending the Saint-Joseph Hospital hypertension clinic N between January 1976 and December 1978 and enrolled in the 0 computerised Artemis system." The methods adopted in this prospective study were similar to those used for predicting fatal or non-fatal cardiovascular complications in cohort studies. ${ }^{56} \stackrel{\infty}{\rightarrow}$ We considered that early detection of patients at high risk of 0 dropping out ${ }^{3}$; might improve the management of patients with hypertension.

Patients and methods

STUDY POPULATION

Between 1 January 1976 and 31 December 1978, 2920 patients $\frac{0}{7}$ were referred to the hospital's outpatient hypertension clinic. Altogether 1346 records were analysed and selected by according to two 
criteria: (a) a recumbent blood pressure, measured after five to 10 minutes' rest during the initial visit, above or equal to $160 \mathrm{~mm} \mathrm{Hg}$ (systolic) or $95 \mathrm{~mm} \mathrm{Hg}$ (diastolic), whether or not hypertension (if present) was being treated; and (b) referral to the clinic for complete management of raised blood pressure and not just for advice.

The mean age of the 1346 selected patients ( 763 men and 583 women) was $50 \cdot 8(\mathrm{SD} 12 \cdot 7)$ years at the initial visit. The mean maximum systolic blood pressure previously recorded was 211 (SD 31) $\mathrm{mm} \mathrm{Hg}$, and the mean systolic and diastolic blood pressures at the first visit were 177 (SD 23) and 104 (SD 13) $\mathrm{mm} \mathrm{Hg}$ respectively. Two hundred and fourteen patients $(15.9 \%)$ had been referred by an occupational health service and $955(71.0 \%)$ by a general practitioner or specialist and $129(9.6 \%)$ had attended the clinic of their own accord. At entry 473 patients $(35.1 \%)$ were receiving hypotensive treatment, defined as any drug, except anxiolytics and vascular protectors, specifically given to reduce blood pressure.

\section{DATA COLLECTION AND RECORDING}

Management of hypertension included a 45 minute initial visit and successive visits lasting 20 to 30 minutes. Patients were evaluated initially either as outpatients or during a short period of admission to hospital.

After two to six months patients attended as outpatients for assessment of their response to treatment; subsequent follow up visits were in most cases carried out at between six months to two year intervals, the long term follow up being mainly the responsibility of the general practitioner. ${ }^{4}$ Drop out was defined as failure to attend for an appointment and to respond to two recall letters sent at an interval of six months.

Patients were classified into three groups according to their occupation: (a) manual workers and employees, $(b)$ middle executives, and $(c)$ senior executives, industrialists, and members of the liberal professions. Patients were also classified according to whether they undertook any regular physical exercise-that is, a sport for at least one hour a week, a walk for an hour a day, or daily manual work. Note was made of whether patients had had a myocardial infarction or stroke, and other conditions noted from the medical histories included asthma, depression, gastroduodenal ulcer, renal lithiasis, and recurrent urinary tract infections.

The variables recorded at the first visit and analysed included the occurrence of headaches or palpitations; evidence of coronary heart disease, either clinical or electrocardiographic, atherosclerosis obliterans of the legs; abnormal bruits on auscultation of blood vessels (carotid, abdominal, or femoral); blood pressure; weight; cigarette consumption; and plasma creatinine, total cholesterol, and blood glucose concentrations. Blood pressure was measured with a mercury sphygmomanometer with patients supine after a rest of five to 10 minutes. The appearance of bruits was taken as the systolic blood pressure and their disappearance as the diastolic blood pressure. The weight index was calculated as body weight $(\mathrm{kg})$ divided by the square of height $(\mathrm{m})$.

\section{STATISTICAL METHODS}

Data on initial and subsequent visits were handled by the computerised Artemis system. ${ }^{4}$ Means were compared with Student's $t$ test and several percentages with the $\chi^{2}$ test. Cumulative actuarial drop out rates (standard error) were estimated by the Kaplan-Meier method. ${ }^{8}$ Information on dead patients was considered to be censored data. In univariate studies of the predictive factors of attendance quantitative variables were divided into five quintiles and the actuarial cumulative drop out rate calculated for each. The logrank method ${ }^{9}$ was used to compare two or more drop out curves and to calculate trends in cases of quantitative variables-for example, systolic blood pressure at first visit-or of ordered qualitative variables-for example, occupational categories. Results were considered to be significant at the $5^{\circ}{ }_{0}$ level.

The logistic model $p+1 /(1+\exp -(\beta 0+\beta i X)$ was used for simultaneous testing of the effect of the variables predictive of drop out or poor blood pressure control at one year. ${ }^{10}{ }^{11}$ Only the variables significant at the $5 \%$ level in the univariate analyses were included in these multivariate analyses. In instances where variables were closely correlated-for example, systolic blood pressure and maximum systolic blood pressure in the history-only the most significant variable after univariate analyses was included in the multivariate analyses-for example, systolic blood pressure. Maximal likelihood estimators were computed by the Newton-Raphson method. ${ }^{10}$ Exclusion of variables from the initial model to build up a final risk function was based on maximum likelihood ratio tests. ${ }^{11}$ The number of expected and observed events was compared in each quintile of expected risk calculated by the logistic risk function. The relative risk for patients with the highest values (those in quintile $V$ ) to those with the lowest (in quintile I) was expressed in terms of the ratio of the rate for $\mathrm{V}$ to the rate for $\mathrm{I}$ (ratio V:I). Finally, the attributable risk (extra risk attributable to a high level of traits) was calculated as the difference between the rate for $\mathrm{V}$ and the rate for I (difference V-I).

\section{Results}

\section{DROP OUT RATES}

All the 1346 selected patients were given appointments at the clinic for either outpatient care or secondary inpatient care. The overall follow up period represented 2246 patient years (mean 1.7 (SD 1.0) years). After one year of follow up 11 of the $1346(0.8 \%)$ patients had died and $209(15.5 \%)$ were lost to follow up. Of these 209 patients, 66 were lost after the first visit $(31.6 \%$ of the drop outs at one year). The cumulative drop out rate estimated by the KaplanMeier method was 14.7 (SD 0.9) at six months, 17.6 (SD 1.0) at one year, 22.3 (SD 1.1) at two years, and 25.9 (SD 1.5) at three years (figure).

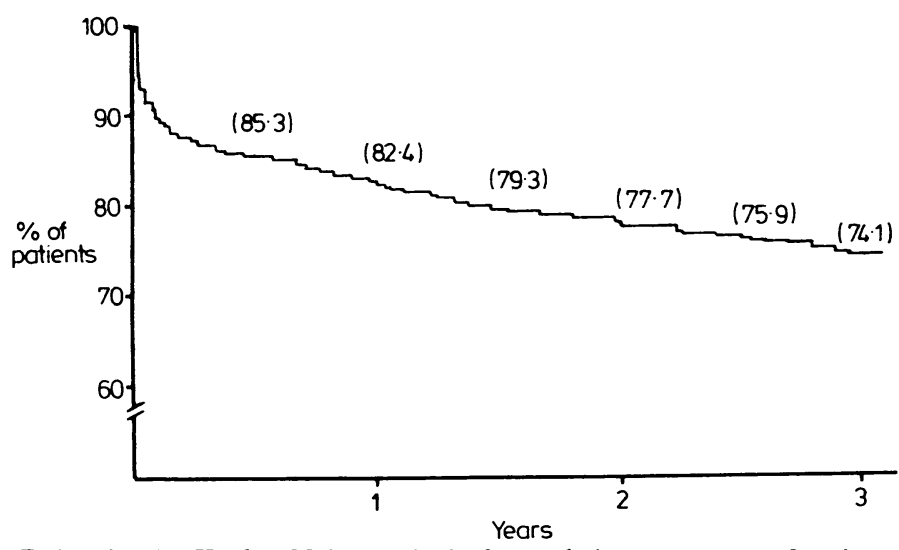

Estimation by Kaplan-Meier method of cumulative percentage of patients followed up.

\section{INITIAL CHARACTERISTICS OF PATIENTS WHO DROPPED OUT}

The characteristics of the 209 patients who dropped out during the first year of follow up were analysed and compared with those of the 1126 patients still under surveillance after one year (table I). The patients who dropped out were more often men and were younger than the compliant patients; they were more often referred as a result of occupational screening than by a general practitioner or specialist, and they more commonly belonged to the lowest occupational categories. A history of stroke or asthma was less common in patients who dropped out; these patients had lower blood pressures than the compliant patients in their history or at entry, were less likely to be receiving hypotensive treatment or to have evidence of coronary heart disease, were more often overweight at entry, and had higher cigarette consumption (all $\mathrm{p}<0.05$ ). History of depression, renal lithiasis, and recurrent urinary infections and the presence of headaches, palpitations, abnormal bruit on vessel auscultation, and leg atherosclerosis obliterans at the first visit were similar in both groups, as were serum creatinine, blood glucose, and cholesterol concentrations.

\section{UNIVARIATE PREDICTION OF LOW COMPLIANCE WITH APPOINTMENTS}

Univariate analysis by the logrank method confirmed the statistical association between most of the above characteristics analysed at entry and the drop out rates estimated by the Kaplan-Meier method. These rates were higher in men than in women (logrank test: $\chi^{2}=7 \cdot 9$, 
$\mathrm{p}<0 \cdot 01)$ and tended to decrease with age $\left(\chi^{2}\right.$ for trend $\left.=11 \cdot 0, \mathrm{p}<0.001\right)$. The drop out rate at one year was $30.4 \%$ in the 214 patients referred by occupational health services and $15.1 \%$ in those referred by other health care workers or who came to the clinic of their own accord $(\mathrm{p}<0.001)$. Among the 801 patients with regular employment at entry the drop out rate was higher in the 399 patients belonging to the lowest occupational category $\left(21.9^{\circ}\right.$, at one year) than in the 136 patients belonging to the highest category $(16.2 \%)$ or the 266 in the middle category $\left(16.6^{\circ}\right)(p<0.05)$. The 72 patients with a history of stroke had a very low drop out rate $\left(7 \cdot 1^{\circ}{ }_{0}\right.$ at one year) compared with the 1274 remaining patients $\left(18.2^{\circ}{ }_{0}, \mathrm{p}<0.05\right)$. Similarly the 61 patients with a history of asthma had a very low drop out rate $\left(5^{\circ}\right.$, at one year) compared with the 1285 non-asthmatic patients $(18.2 \%$, $\mathrm{p}<0.01)$. A history of depression, renal lithiasis, or recurrent urinary infections and evidence at entry of coronary heart disease or atherosclerosis obliterans of the legs did not significantly affect drop out rates. The increased drop out rate in the 54 patients with a history of gastroduodenal ulcer $(26.2 \%$ at one year) was at the limit of signi- ficance $\left(\chi^{2}=3 \cdot 62, p<0 \cdot 1\right)$ compared with the rate among the remaining 1292 patients $(17 \cdot 2 \%)$

The drop out rate significantly decreased with systolic blood pres 3 sure-that is, with the maximum previous systolic blood pressuree $(p<0.01)$ and the systolic blood pressure at entry $(p<0.01)$-but $c$ not with the diastolic blood pressure at entry. The drop out rate was̄ lower in patients taking hypctensive drugs at entry $(11.4 \%$ ) than in untreated patients $\left(21 \cdot 1^{\circ}, \mathrm{p}<0 \cdot 001\right)$. Among the 473 patients being treated at entry the drop out rate was independent of the number of hypotensive drugs taken. Drop out rates were positively associated $m$ with the weight index $(p<0.001)$ and cigarette consumption at entrye $(p<0.01)$ but were independent of physical activity.

\section{MULTIVARIATE PREDICTION OF ATTENDANCE}

Multivariate analysis with the logistic model took account of the following 11 factors: sex (coded as 1 for men and 0 for women), age, $\varrho$

TABLE I-Factors predictive of low compliance with appointments $(n=1335)$

\begin{tabular}{|c|c|c|c|}
\hline Factors & Patients followed up & Drop outs & $\mathbf{p}$ \\
\hline $\begin{array}{l}\text { No of patients } \\
\text { No }(\%) \text { of men } \\
\text { Mean (SD) age (years) } \\
\text { No }(\%) \text { referred by worksite doctors } \\
\text { No of manual workers, employees (and as \% of workers) } \\
\text { No (\%) receiving antihypertensive treatment at first visit } \\
\text { Patient's history: }\end{array}$ & $\begin{array}{l}1126 \\
621^{2}(55 \cdot 2) \\
51 \cdot 4(12 \cdot 5) \\
152 \quad(13 \cdot 5) \\
315 \quad(47 \cdot 9) \\
423 \quad(37 \cdot 6)\end{array}$ & $\begin{array}{lc}209 \\
136 & (65 \cdot 1) \\
47 \cdot 4 & (13 \cdot 5) \\
62 & (29 \cdot 7) \\
82 & (58 \cdot 6) \\
45 & (21 \cdot 5)\end{array}$ & $\begin{array}{l}<0.01 \\
<0.001 \\
<0.001 \\
<0.05 \\
<0.001\end{array}$ \\
\hline $\begin{array}{l}\text { Mean (SD) maximum systolic blood pressure }(\mathrm{mm} \mathrm{Hg}) \\
\text { No }(\%) \text { with history of: }\end{array}$ & $211.9(30 \cdot 9)$ & $205 \cdot 6(29 \cdot 1)$ & $<0.01$ \\
\hline $\begin{array}{l}\text { Stroke } \\
\text { Myocardial infarction } \\
\text { Asthma } \\
\text { Gastroduodenal ulcer } \\
\text { Depression } \\
\text { Renal lithiasis } \\
\text { Recurrent urinary infections }\end{array}$ & $\begin{array}{rr}68 & (6 \cdot 0) \\
20 & (1 \cdot 8) \\
58 & (5 \cdot 2) \\
41 & (3 \cdot 6) \\
113 & (10 \cdot 0) \\
126 & (11 \cdot 2) \\
139 & (12 \cdot 3)\end{array}$ & $\begin{array}{rr}3 & (1 \cdot 4) \\
1 & (0 \cdot 5) \\
2 & (1 \cdot 0) \\
12 & (5 \cdot 7) \\
29 & (13 \cdot 9) \\
16 & (7 \cdot 7) \\
25 & (12 \cdot 0)\end{array}$ & $\begin{array}{l}<0.01 \\
\text { NS } \\
<0.01 \\
\text { NS } \\
\text { NS } \\
\text { NS } \\
\text { NS }\end{array}$ \\
\hline 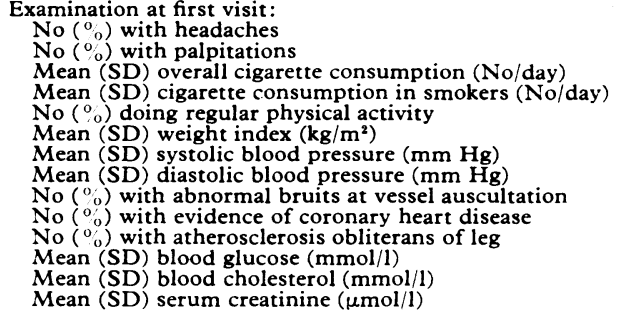 & $\begin{array}{l}472(41 \cdot 9) \\
367(32 \cdot 6) \\
3 \cdot 6(8 \cdot 3) \\
13 \cdot 3(11 \cdot 2) \\
270(24 \cdot 0) \\
25 \cdot 2(4 \cdot 0) \\
178 \cdot 0(23 \cdot 1) \\
104 \cdot 8(12 \cdot 8) \\
205(18 \cdot 2) \\
68(6 \cdot 0) \\
37(3 \cdot 3) \\
5 \cdot 61(1 \cdot 28) \\
6 \cdot 13(1 \cdot 24) \\
99 \cdot 5(91 \cdot 9)\end{array}$ & $\begin{array}{l}81(38 \cdot 8) \\
57(27 \cdot 3) \\
6 \cdot 1(11 \cdot 9) \\
18 \cdot 6(14 \cdot 1) \\
41(19 \cdot 6) \\
26 \cdot 5(4 \cdot 6) \\
171 \cdot 1(20 \cdot 8) \\
102 \cdot 5(11 \cdot 9) \\
32(15 \cdot 3) \\
5(2 \cdot 4) \\
7(3 \cdot 4) \\
5 \cdot 65(1 \cdot 32) \\
6 \cdot 14(1 \cdot 09) \\
97 \cdot 1(82 \cdot 7)\end{array}$ & $\begin{array}{l}\text { NS } \\
\text { NS } \\
<0.01 \\
<0.01 \\
\text { NS } \\
<0.001 \\
<0.001 \\
<0.01 \\
\text { NS } \\
<0.05 \\
\text { NS } \\
\text { NS } \\
\text { NS } \\
\text { NS }\end{array}$ \\
\hline
\end{tabular}

Conversion: SI to traditional units-Glucose: $1 \mathrm{mmol} / 1 \approx 18 \mathrm{mg} / 100 \mathrm{ml}$. Cholesterol: $1 \mathrm{mmol} / 1 \approx 38.7 \mu \mathrm{g} / 100 \mathrm{ml}$. Creatinine: $1 \mu \mathrm{mol} / 1$ $\approx 11.3 \mu \mathrm{g} / 100 \mathrm{ml}$.

TABLE II-Variables in eight factor multiple logistic function to predict drop out at one year (1270 patients, 202 drop outs)

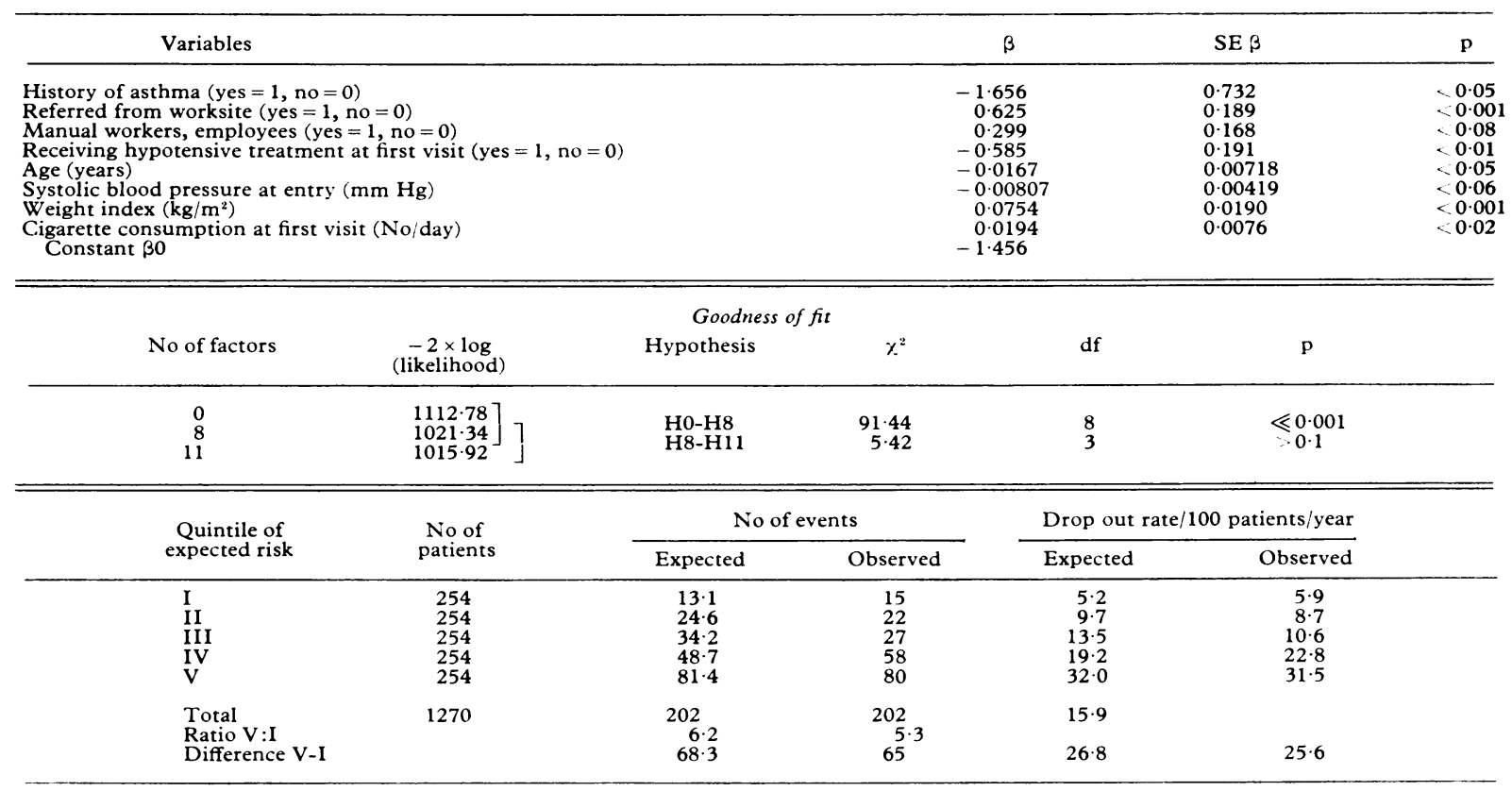


antihypertensive treatment at entry (yes $=1$, no $=0$ ), referring modality (occupational health service $=1$, other $=0$ ), occupational category (manual workers and employees $=1$, others $=0$ ), history of stroke, history of asthma, evidence at entry of coronary heart disease (yes $=1$, no $=0$ ), and systolic blood pressure, weight index, and daily cigarette consumption at entry. The complete set of information was available for 1270 of the $1346(94.3 \%)$ patients studied. When this model was used the significant factors $(p<0.05)$ explaining drop out were by decreasing order of statistical importance; weight index, referring modality, antihypertensive treatment at entry, cigarette consumption, history of asthma, and age. Sex, history of stroke, and coronary heart disease were no longer significant at the $0.5 \%$
$12 \cdot 1$ (SD 1.4) months. Mean systolic blood pressure at one year was $145 \cdot 1$ (SD $25 \cdot 1$ ) $\mathrm{mm} \mathrm{Hg}$ and mean diastolic blood pressure 87.7 (SD $11.0) \mathrm{mm} \mathrm{Hg}$. Of the 981 patients examined, $910(92.8 \%)$ had a supine diastolic blood pressure of less than $105 \mathrm{~mm} \mathrm{Hg}$ and 714 $(72.8 \%)$ of less than $95 \mathrm{~mm} \mathrm{Hg}$. Six hundred and sixty nine patients $(68.2 \%)$, whose blood pressure was defined as well controlled, had a systolic blood pressure less than $160 \mathrm{~mm} \mathrm{Hg}$ and a diastolic blood pressure less than $95 \mathrm{~mm} \mathrm{Hg}$ at one year. The remaining 312 patients were considered to have poorly controlled blood pressure. Systolic and diastolic blood pressures at one year were highly and positively correlated with systolic and diastolic blood pressures at entry, as well as with the fall in systolic and diastolic pressures (all $\mathrm{p}<0.001$ ).

TABLE III-Factors predictive of insufficient blood pressure control at one year (981 patients)

\begin{tabular}{|c|c|c|c|}
\hline \multirow[b]{2}{*}{ Factors } & \multicolumn{2}{|c|}{ Blood pressure: } & \multirow[b]{2}{*}{$\mathrm{p}$} \\
\hline & $<160 / 95 \mathrm{~mm} \mathrm{Hg}$ & $\begin{array}{c}\geqslant 160 \mathrm{~mm} \mathrm{Hg} \text { systolic } \\
\text { or } \geqslant 95 \mathrm{~mm} \mathrm{Hg} \text { diastolic }\end{array}$ & \\
\hline $\begin{array}{l}\text { No of patients } \\
\left.\text { No (" }{ }^{\circ}\right) \text { of men } \\
\text { Mean (SD) age (years) } \\
\text { No (") }(0) \text { referred by worksite doctors } \\
\text { No of manual workers, employees (and as \% of workers) } \\
\text { No (oo) receiving antihypertensive treatment at first visit } \\
\text { Patient's history: }\end{array}$ & $\begin{array}{lr}669 & \\
371 & (55 \cdot 5) \\
49 \cdot 7 & (11 \cdot 6) \\
102 & (15 \cdot 2) \\
200 & (48 \cdot 0) \\
222 & (33 \cdot 2)\end{array}$ & $\begin{array}{ll}312 & \\
168 & (53 \cdot 9) \\
55 \cdot 2 & (12 \cdot 4) \\
35 & (11 \cdot 2) \\
66 & (47 \cdot 8) \\
142 & (45 \cdot 5)\end{array}$ & $\begin{array}{l}\text { NS } \\
<0 \cdot 001 \\
\text { NS } \\
\text { NS } \\
<0 \cdot 001\end{array}$ \\
\hline $\begin{array}{l}\text { Mean (SD) maximum systolic blood pressure }(\mathrm{mm} \mathrm{Hg}) \\
\left.\text { No (o. }{ }^{0}\right) \text { with history of: }\end{array}$ & $207 \cdot 7(28 \cdot 2)$ & $222 \cdot 3(33 \cdot 9)$ & $<0.001$ \\
\hline $\begin{array}{l}\text { Stroke } \\
\text { Myocardial infarction } \\
\text { Asthma } \\
\text { Gastroduodenal ulcer } \\
\text { Depression } \\
\text { Renal lithiasis } \\
\text { Recurrent urinary infections } \\
\text { Examination at first visit: }\end{array}$ & $\begin{array}{rr}34 & (5 \cdot 1) \\
9 & (1 \cdot 3) \\
37 & (5 \cdot 5) \\
23 & (3 \cdot 4) \\
69 & (10 \cdot 3) \\
77 & (11 \cdot 5) \\
81 & (12 \cdot 1)\end{array}$ & $\begin{array}{lr}27 & (8 \cdot 7) \\
10 & (3 \cdot 2) \\
12 & (3 \cdot 8) \\
15 & (4 \cdot 8) \\
26 & (8 \cdot 3) \\
36 & (11 \cdot 5) \\
28 & (9 \cdot 0)\end{array}$ & $\begin{array}{l}<0.05 \\
<0.05 \\
\text { NS } \\
\text { NS } \\
\text { NS } \\
\text { NS } \\
\text { NS }\end{array}$ \\
\hline 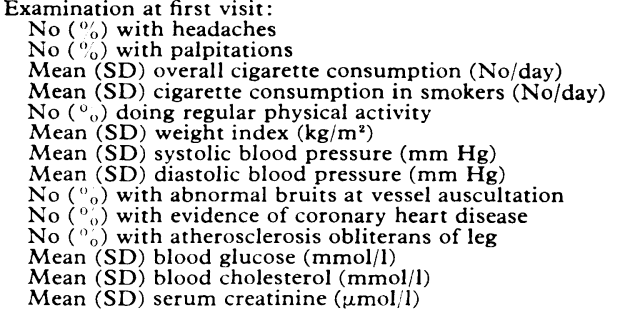 & $\begin{array}{l}279(41 \cdot 7) \\
218(32 \cdot 6) \\
3 \cdot 7(8 \cdot 0) \\
13 \cdot 3(10 \cdot 1) \\
170(25 \cdot 4) \\
25 \cdot 2(3 \cdot 9) \\
174 \cdot 1(20 \cdot 6) \\
104 \cdot 6(12 \cdot 7) \\
104 \quad(15 \cdot 5) \\
27(4 \cdot 0) \\
12(1 \cdot 8) \\
5 \cdot 52(1 \cdot 03) \\
6.10(1 \cdot 28) \\
96.0(89 \cdot 4)\end{array}$ & $\begin{array}{l}136(43 \cdot 6) \\
102(32 \cdot 7) \\
3 \cdot 6(8 \cdot 7) \\
12 \cdot 9(12 \cdot 5) \\
67(21 \cdot 5) \\
25 \cdot 4(4 \cdot 1) \\
181 \cdot 1(24 \cdot 7) \\
106 \cdot 6(13 \cdot 0) \\
73(23 \cdot 4) \\
30(9 \cdot 6) \\
19(6 \cdot 1) \\
5 \cdot 82(1 \cdot 73) \\
6 \cdot 26(1 \cdot 19) \\
106 \cdot 1(94 \cdot 7)\end{array}$ & $\begin{array}{l}\text { NS } \\
\text { NS } \\
\text { NS } \\
\text { NS } \\
\text { NS } \\
\text { NS } \\
<0.001 \\
<0.05 \\
<0.01 \\
<0.001 \\
<0.001 \\
<0.01 \\
\text { NS } \\
\text { NS }\end{array}$ \\
\hline
\end{tabular}

Conversion: $S$
$11.3 \mu \mathrm{g} / 100 \mathrm{ml}$.

level in this multivariate analysis. Occupational category and systolic blood pressure at entry were at the limit of significance $(p<0 \cdot 1)$.

The six factor model, which took account of only the factors significant at the $5 \%$ level, was significantly less predictive than the 11 factor model $(p<0.05)$ and could not be satisfactorily used to predict non-compliance with appointments. On the other hand, the eight factor model, which took account of the factors significant at the $10^{\circ}$, level, was as predictive as the complete 11 factor model and yielded a satisfactory fit between expected numbers of drop outs (calculated from the logistic function) and the number of drop outs observed in each quintile of the 1270 patients studied (table II). Thus the risk of drop out at one year in the lowest quintile of expected risk was estimated as 5.9/100 compared with an estimated risk of $32 \cdot 0 / 100$ in the patients in the top quintile, a sixfold increase comparable with the risk ratio calculated during multivariate prediction of major coronary events, such as those reported by the Pooling Project Research Group. ${ }^{5}$

For the subgroup of 819 patients not undergoing hypotensive treatment at entry, the results obtained with the logistic model were similar to those obtained for the complete group of 1270 patients. The factors significant at the $5 \%$, level were weight index, referring modality, age, occupation, and cigarette consumption. For this subgroup, history of asthma was at the limit of significance $(p<0 \cdot 1)$ but not systolic blood pressure at entry.

\section{BLOOD PRESSURE CONTROL AT ONE YEAR}

Of the 1126 patients followed up at the clinic for one year or more, 981 were examined between eight and 18 months after their initial visit. The values recorded during the visit closest to one year after the initial visit were regarded as one year values. The mean period elapsing between the first visit and the one year visit thus defined was

\section{PREDICTION OF BLOOD PRESSURE CONTROL}

The initial characteristics of the 312 patients whose blood pressure was poorly controlled at one year were compared with those of the 669 patients whose blood pressure was well controlled (table III). Sex distribution was similar in both groups, as was the distribution of social categories and the modalities by which patients were referred to the clinic. Patients with poorly controlled blood pressure were older, their maximum past systolic blood pressure and the diastolic blood pressure at their first visit were higher, and they were more likely to have histories of major cardiovascular events and higher blood glucose concentrations at entry (all $\mathrm{p}<0.05$ ). Body weight index and cigarette consumption were similar in both groups, as were serum creatinine, cholesterol, and uric acid concentrations.

The eight variables included in the multivariate logistic function of blood pressure prediction at one year were age, history of stroke, hypotensive treatment, and systolic blood pressure at entry, evidence at entry of coronary heart disease and atherosclerosis obliterans of the legs, abnormal bruit on vessel auscultation (carotid, abdominal, or femoral), and blood glucose concentration (table IV). The variables that contributed most $(p<0.05)$ were by decreasing order of importance systolic blood pressure, age, and blood glucose concentrations. Evidence of coronary heart disease was a factor at the limit of significance in this eight factor model $(p<0 \cdot 1)$. In a four factor model, which included systolic blood pressure, age, blood glucose concentration, and evidence of coronary heart disease, all these four factors were significant at the $5 \%$ level and gave a good fit between observed and expected results.

\section{Discussion}

In this analysis we examined two criteria that can be easily and precisely assessed for evaluating the effectiveness of medical 
TABLE IV-Variables in four factor multiple logistic function to predict insufficient blood pressure control at one year (964 patients)

\begin{tabular}{lccc}
\hline \multicolumn{1}{c}{ Variables } & $\beta$ & SE $\beta$ & p \\
\hline Evidence of coronary heart disease (yes $=1$, no $=0)$ & 0.712 & 0.02 \\
Age (years) & 0.0205 & 0.283 & 0.01 \\
Systolic blood pressure $(\mathrm{mm} \mathrm{Hg})$ & 0.0228 & 0.0067 & 0.001 \\
Blood glucose (mmol/1) & 0.120 & 0.0035 & 0.05 \\
Constant $\beta 0$ & -6.638 & 0.0526 & \\
\hline \hline
\end{tabular}

\begin{tabular}{|c|c|c|c|c|c|}
\hline \multicolumn{6}{|c|}{ Goodness of fit } \\
\hline $\begin{array}{l}\text { No of } \\
\text { factors }\end{array}$ & $\begin{array}{c}-2 \times \log \\
\text { (likelihood) }\end{array}$ & Hypothesis & $x^{2}$ & df & $\mathrm{p}$ \\
\hline \multirow{2}{*}{$\begin{array}{l}0 \\
4 \\
8\end{array}$} & \multirow{2}{*}{$\left.\begin{array}{l}1206 \cdot 36 \\
1104 \cdot 14 \\
1097 \cdot 92\end{array}\right]$} & $\mathrm{HO}-\mathrm{H} 4$ & $102 \cdot 22$ & 4 & $\ll 0.001$ \\
\hline & & $\mathrm{H} 4-\mathrm{H} 8$ & $6 \cdot 22$ & 4 & 0.01 \\
\hline \multirow{2}{*}{$\begin{array}{l}\text { Quintile of } \\
\text { expected risk }\end{array}$} & \multirow{2}{*}{$\begin{array}{c}\text { No of } \\
\text { patients }\end{array}$} & \multicolumn{2}{|c|}{ No of events } & \multicolumn{2}{|c|}{ Drop out rate/ 100 patients/year } \\
\hline & & Expected & Observed & Expected & Observed \\
\hline $\begin{array}{l}\text { I } \\
\text { II } \\
\text { III } \\
\text { IV } \\
\text { V } \\
\text { Total } \\
\text { Ratio V:I }\end{array}$ & $\begin{array}{l}192 \\
193 \\
193 \\
193 \\
193 \\
964\end{array}$ & $\begin{array}{c}29 \cdot 2 \\
42 \cdot 8 \\
54 \cdot 6 \\
71 \cdot 4 \\
109 \cdot 0 \\
307 \\
3 \cdot 7\end{array}$ & $\begin{array}{c}31 \\
42 \\
54 \\
72 \\
108 \\
307 \\
3.5\end{array}$ & $\begin{array}{l}15 \cdot 2 \\
22 \cdot 2 \\
28 \cdot 3 \\
37 \cdot 0 \\
56 \cdot 5 \\
31 \cdot 8\end{array}$ & $\begin{array}{l}16 \cdot 1 \\
21 \cdot 8 \\
28 \cdot 0 \\
37 \cdot 3 \\
56 \cdot 0\end{array}$ \\
\hline
\end{tabular}

management ${ }^{3}$-namely, compliance with appointments and control of blood pressure. Lack of compliance does not necessarily indicate absence of treatment and blood pressure control, since patients may be followed up by other health care systems to which they may have easy access. Nevertheless, noncompliance with appointments emerges as the most serious form of failure in the medical management of hypertension. On the other hand, poor blood pressure control in patients who were followed up was responsible for an excessively high incidence of cardiovascular events compared with that in patients with well controlled blood pressure, even though inadequate control of blood pressure may partially prevent cardiovascular complications. ${ }^{12}$

Many factors may influence compliance, including the characteristics of the health care delivery system, the attitudes of the patients, and the interaction between them. Our hypertension clinic is specifically organised to minimise the problems of compliance $^{4}:$ it has adopted an automated appointment system to reduce waiting and direct mailing of recall letters to the patient as well as to his general practitioner; provides information leaflets on hypertension, its management, and the organisation of the clinic; and arranges appointments that are long enough for the patient and doctor to communicate. Since the amount of attention given by doctors to the problems of compliance is a factor influencing results, ${ }^{13}$ all clinic doctors have been specially trained to deal with these problems. Despite these efforts to minimise non-compliance the residual percentage of patients lost to follow up $(15.5 \%$ at one year) was still close to that observed in other studies. ${ }^{14-18}$ This may indicate that further studies of non-compliance are necessary, including a statistical analysis of the risk factors by using standardised, structured, computerised medical records.

A previous study using the computerised Artemis system showed that of the 17 questions on the patients' past history that had been evaluated, all 17 had been answered in over $97^{\circ}$ \% of cases. In the present study multivariate analysis included 11 variables, and complete information was obtained for 1270 $\left(94.3^{\circ}\right)$ of the 1346 patients. A similarly high proportion of completed records was obtained by Bulpitt et al, who used standardised medical records in three hypertension clinics in England, which enabled them to analyse accurately mortality risk factors in 2587 hypertensive patients followed up for an average of four years. ${ }^{6}$

Among the 27 variables analysed here several-including obesity and cigarette consumption-were associated with a high drop out rate. Epidemiological population studies generally show a positive correlation between weight and blood pressure. ${ }^{19}$
Reduction of weight is therefore considcred to be an importani method of reducing blood pressure. Cigarette consumption iso also a definite independent cardiovascular risk factor, andoo stopping smoking is therefore a major objective in programmes designed to reduce the cardiovascular risk. The excessive drop? out rate in our study in obese patients and smokers suggests that health counselling and treatment have little effect in thes groups. In a large scale screening and treatment programme for hypertension participation was lower in smokers than nonsmokers, whatever their sex, age, or race. ${ }^{1618}$ The excessive ${ }^{\omega}$ drop out rate among obese subjects and smokers may be explained by at least two factors: excess body weight and ciga rette consumption are characteristics acquired before consultation at a hypertension clinic and may reflect an uncooperative attitude to the medical prevention of cardiovascular risks $\mathbb{D}$ and the medical management provided at a clinic may not be well adapted to patients presenting with risk factors other than hypertension. Low compliance reflects the difficulties the patient has in carrying out the many recommendations of their doctors?

Patients referred to hypertension clinics by occupationa health services have higher drop out rates than those referreds by general practitioners or specialists. This may be because some patients do not feel the need for a family doctor and thus after the initial consultation at the hypertension clinic. there is no back up medical care, which encourages high drop⿳⺈ out rates.

The higher drop out rate in patients in the lower sociab categories is of major concern. Patients attending the St Joseph hypertension clinic tend to come from the higher socioeconomic groups, regardless of the method of referral. ${ }^{20}$ The reason for this is most probably financial, since for most patients only $80 \%$ of health expenses are refunded by the French social security system. Increasing accessibility of care by providing blood $\omega$ pressure control services at places of work has proved to be cost effective. ${ }^{21}$ The impact of medical advice and information at the clinic also depends on the patients' educational level $\mathbb{S}_{\mathcal{E}}$ which is correlated with their occupational category and income and is predictive of compliance. ${ }^{19} 2223$

In the present study patients with a history of asthma usually命 attended the clinic more regularly than non-asthmatic patients $\frac{\rho}{\mathrm{D}}$ previous contact with a health delivery system is thought to encourage compliance. ${ }^{3}$ In our study, however, this was not always the case since a history of depression or renal lithiasi 8 had no predictive value in relation to attendance.

The severity of hypertension, as assessed by the maximune systolic blood pressure ever recorded and blood pressur? readings at the first visit, was significantly lower in patients 
who dropped out. Although these variables of severity may affect both the cooperation of the patient and the attention given by the doctor, their statistical significance partly disappeared in the multivariate analysis when the other significant factors including age were taken into account. Subjective assessment of severity-based on symptoms commonly associated with hypertension such as headaches and palpitationshad no predictive value as regards compliance with appointments. The lower proportion of patients who were not receiving treatment at their first visit among the patients who later dropped out than among those followed up might be explained by the fact that the hypertension was less severe in the patients who dropped out. This difference in the proportion of patients not initially receiving treatment remained significant after adjustment for age, sex, and severity of hypertension, however, and might reflect the attitude of patients who drop out, who may have refused treatment for a long time before attending the clinic.

Blood pressure recordings at one year in the patients treated in the clinic showed that diastolic blood pressures fell from a mean of 104.0 to $87.7 \mathrm{~mm} \mathrm{Hg}$, a fall comparable with that observed after one year in the Hypertension Detection and Follow up Program (101 to $87 \mathrm{~mm} \mathrm{Hg})^{12}$ and in three British hypertension clinics $(110$ to $95 \mathrm{~mm} \mathrm{Hg}){ }^{24}$ Despite treatment schedules using up to four hypotensive drugs simultaneously blood pressure in many patients $\left(31.8^{\circ}\right)$ remained uncontrolled at one year (systolic blood pressure $\geqslant 160$ or diastolic blood pressure $\geqslant 95 \mathrm{~mm} \mathrm{Hg}$ ). This figure is probably a biased overestimation, however, since the drop out rate was negatively correlated with the initial blood pressure and the magnitude of the fall in pressure was positively correlated with the initial pressure.

Patients in whom blood pressure was poorly controlled tended to be older, to have higher blood pressure, and to have a history of atherosclerotic complications (vascular bruits, ischaemic heart disease, or atherosclerosis obliterans of the legs) compared with the patients in whom it was well controlled; differences between the two groups remained significant after adjustment for age. Too few patients had an abnormal plasma creatinine concentration for the effect of renal insufficiency to be assessed. Interestingly, two significant factors-age and systolic blood pressurewere also found to be predictive of cardiovascular death in the British study of 2587 treated hypertensive patients. ${ }^{6}$ These results indicate that the initial severity of hypertension may increase the cardiovascular risk because of the severity of the initial cardiovascular damage (even if subclinical) and the difficulty of reducing blood pressure to a satisfactory level. Similarly, body weight and plasma cholesterol concentrations, which were not predictors of blood pressure control at one year in the present study, were not predictive factors of cardiovascular death in the British study. A major discrepancy between the studies in the factors predictive of death and blood pressure control is cigarette consumption; in this study it was not predictive of blood pressure control but in the British study it was a definite cardiovascular mortality risk factor. This may not be surprising, since in most epidemiological studies cigarette smoking appears to be an independent cardiovascular risk factor despite the absence of any correlation between smoking and blood pressure. The excessive drop out rate in smokers may contribute to the increased cardiovascular risk, even if it has no direct influence on the response to antihypertensive treatment.

The ability to predict low attendance as early as the first visit and difficulties in controlling hypertension have important practical consequences. Doctors frequently fail to predict which of their patients will fail to comply with treatment and advice. ${ }^{325}$ Detecting those at high risk of dropping out should increase the doctor's vigilance and alter his approach to the patient. These two measures should increase attendance. ${ }^{3}$ ' Comparative trials of strategies to improve compliance should be conducted among those populations most likely to drop out instead of among the general hypertensive population. In hypertension clinics where new hypotensive drugs are tried out the subpopulations at low risk of dropping out should be identified and included in these studies. In any case, we emphasise that the validity of any prediction equation extracted from a specific population such as ours, should be tested among other populations with access to differing patterns of medical care.

This study was supported in part by grants from the French Ministry of Health, Paris VI University, and the Fond de la Recherche Médicale. We are also indebted to Drs M B Ducrocq and A Tugaye of the medical staff; Mr R Legeais and Mrs A-M Renoir, respectively directors of the Saint-Joseph and Broussais hospitals; our past and present nurses; Messrs J C Hirel, P Le Beux, C Berger, F Goupy, and F Leroy and all the staff of the CITI2 computing centre; and Mrs R M Dreyfus and Mr M Depardieu for their help in preparing the manuscript.

\section{References}

${ }^{1}$ Sackett DL. Patients and therapies: getting the two together. $N$ Engl $\mathcal{f}$ Med 1978;296:278-9.

2 Stason WB, Weinstein MC. Allocation of resources to manage hypertension. N Engl f Med 1977;296:732-9.

${ }^{3}$ Haynes RB, Mattson ME, Chobanian AV, et al. Management of patient compliance in the treatment of hypertension. Report of the NHLBI working group. Hypertension 1982;4:415-23.

${ }^{4}$ Degoulet P, Ménard J, Berger C, Plouin PF, Devriès C, Hirel JC. Hypertension management: the computer as a participant. Am f Med 1980 68:559-67.

${ }^{5}$ Pooling Project Research Group. Relationship of blood pressure, serum cholesterol, smoking habit, relative weight and ECG abnormalities to incidence of major coronary events: final report of the Pooling Project. 7 Chronic Dis 1978;31:201-306.

${ }^{6}$ Bulpitt CJ, Beilin LJ, Clifton P, et al. Risk factors for death in treated hypertensive patients. Report from the DHSS Care Computing Project. Lancet 1979; ii:134-7.

${ }^{7}$ Working Group to Define Critical Patients Behaviors in High Blood Pressure Control. Patient behaviors for blood pressure control: guidelines for professionals. FAMA 1979;241:2534-7.

${ }^{8}$ Kaplan EL, Meier P. Non-parametric estimation from incomplete observation. Fournal of the American Statistics Association 1958;53:457-81.

${ }^{9}$ Peto R, Pike MC, Armitage P, et al. Design and analysis of randomized clinical trials requiring prolonged observation of each patient. $\mathrm{Br} \mathcal{F}$ Cancer $1977 ; 35: 1-39$.

${ }^{10}$ Cox DR. The analysis of binary data. London: Methuen, 1970.

11 Kendall M, Stuart A. The advance theory of statistics. Vol 2. Inference and relationship. 4th ed. London: Charles Griffin, 1979;244-47.

${ }^{12}$ Hypertension Detection and Follow-up Program Cooperative Group. Five year findings of the hypertension detection and follow-up program: I. Reduction in mortality of persons with high blood pressure, including mild hypertension. F $A M A$ 1979; 242:2562-71.

13 Inui TS, Yourtee EL, Williamson JW. Improved outcomes in hypertension after physician tutorials. Ann Intern Med 1976;84:646-51.

14 Engelland AL, Alderman MH, Powell HB. Blood pressure control in private practice: a case report. Am f Public Health 1979;69:25-9.

15 Andersson O, Berglund G, Hansson L, et al. Organization and efficacy of an outpatient hypertension clinic. Acta Med Scand 1978;203:391-8.

${ }^{16}$ Hypertension Detection and Follow-up Program Cooperative Group. Patient participation in an hypertension control program. $\mathcal{F} A M A$ 1978;239:1507-14.

17 Australian Therapeutic Trial in Mild Hypertension. Report by the management committee. Lancet $1980 ; \mathrm{i}: 1261-7$.

18 Smith EO, Curb JD, Hardy RJ, Hawkins CM, Tyroler HA. Clinic attendance in the Hypertension Detection and Follow-up Program. Hypertension 1982;4:710-5.

19 Tobian L. Hypertension and obesity. N Engl f Med 1978;298:46-7.

${ }^{20}$ Degoulet $P$, Devriès C, Wolf JP, Plouin PF, Ménard J. L'accès aux soins de l'hypertendu: influence des catégories socio-professionnelles. Nouv Presse Med 1980;9:15-9.

${ }^{21}$ Logan AG, Milne BJ, Achber C, Campbell WP, Haynes RB. Costeffectiveness of a work-site hypertension treatment program. Hypertension $1981 ; \mathbf{3}: 211-8$

22 Nelson EC, Stason WB, Neutra RR, Solomon HS. Identification of the noncompliant hypertensive patient. Prev Med 1980;9:504-17.

${ }^{23}$ Shulman N, Cutter G, Daugherty R, et al. Correlates of attendance and compliance in the Hypertension Detection and Follow-up Program. Controlled Clin Trials 1982;3:13-27.

${ }^{24}$ Beilin LJ, Bulpitt CJ, Coles EC, et al. Long-term antihypertensive drug treatment and blood pressure control in three hospital hypertension clinics. Br Heart f 1980;43:74-9.

${ }^{25}$ Mushlin AI, Appel FA. Diagnosing patient non compliance. Arch Intern Med 1977;137:318-21.

(Accepted 10 March 1983) 